\title{
Article \\ Human Toxicological Impacts in Life Cycle Assessment of Circular Economy of the Built Environment: A Case Study of Denmark
}

\author{
Caroline Wielandt Egemose $^{1}$, Diane Bastien ${ }^{2}$, Xavier Fretté ${ }^{3}$, Morten Birkved ${ }^{4, *}$ and Joshua L. Sohn ${ }^{4}$ D \\ 1 Rambøll Danmark A/S, Englandsgade 25, DK-5100 Odense, Denmark; cwe@ramboll.dk \\ 2 SDU Life Cycle Engineering, Department of Technology and Innovation, University of Southern Denmark, \\ DK-5230 Odense, Denmark; dib@iti.sdu.dk \\ 3 Nature Energy Biogas, Ørbækvej 260, DK-5220 Odense, Denmark; xfr@nature-energy.com \\ 4 SDU Life Cycle Engineering, Department of Green Technology, University of Southern Denmark, \\ DK-5230 Odense, Denmark; joss@igt.sdu.dk \\ * Correspondence: morb@igt.sdu.dk
}

check for

updates

Citation: Egemose, C.W.; Bastien, D.;

Fretté, X.; Birkved, M.; Sohn, J.L.

Human Toxicological Impacts in Life

Cycle Assessment of Circular

Economy of the Built Environment: A

Case Study of Denmark. Buildings

2022, 12, 130. https://doi.org/

10.3390/buildings12020130

Academic Editor: Francesco

Colangelo

Received: 13 December 2021

Accepted: 23 January 2022

Published: 27 January 2022

Publisher's Note: MDPI stays neutral with regard to jurisdictional claims in published maps and institutional affiliations.

Copyright: (C) 2022 by the authors. Licensee MDPI, Basel, Switzerland. This article is an open access article distributed under the terms and conditions of the Creative Commons Attribution (CC BY) license (https:// creativecommons.org/licenses/by/ $4.0 /)$.

\begin{abstract}
The circular economy has become an important topic in the building industry, and life cycle assessment (LCA) is often used to quantify its benefits. Through chemical analysis, this article demonstrates that the current LCA is not yet well-adapted to assess the circular economy of building materials and components. It is shown that current inventory data and models are insufficient because they do not consider the uptake and emission of chemicals during use, the migration of chemicals within the value chain across the multiple phases in the circular economy, and because current characterization models lack a large fraction of the potentially emitted chemicals from said uptake and emission identified in the tested building material samples. Thus, it is shown that impacts relevant for LCA in the circular economy of buildings remain unaddressed because they are currently either omitted in the LCA that covers a limited number of impact indicators, or are ostensibly covered in the LCA covering a full set of indicators but missed due to inadequate characterization models. To ameliorate this, a definition of embedded toxicity and its relationship to the toxicological footprint is presented and a method for measurement is proposed, illustrating how assessing embedded toxicity can yield information for facilitating safe building-material reuse. Finally, a suggestion for the improvement of life cycle impact assessment methods is proposed.
\end{abstract}

Keywords: life cycle assessment; toxicity; buildings; circular economy; embedded toxicity; embodied toxicity; building materials; life cycle impact assessment; human health; indoor air quality

\section{Introduction}

In the built environment, conventional life cycle assessment (LCA) can be used to assess the environmental impacts of building materials from cradle-to-grave in order to assist in the selection of materials, components, and designs based on environmental performance indicators [1]. Conventional LCA, as applied within the built environment, was developed for the assessment of product systems following a linear economic life cycle (i.e., production, use, and disposal of material) [2]. For products and services with long service life, like buildings, and in other areas of LCA, such as co-production, LCA has been adapted to enable its use. Additionally, LCA has had to be adapted to product systems that include extensive use phases where emissions might occur [3]. More specifically, in relation to the topic of this discussion, the building industry is moving towards a circular economy [4]. This shift requires prioritization based on environmental and performance criteria to ensure that materials/components for the built environment are chosen while considering both previous and future uses for optimizing their environmental performance. This accounting for both previous and future uses of materials can be problematic from an 
LCA methodological perspective (see e.g., [5]). Historically, the environmental performance assessment of building materials/components, as well as entire buildings, has focused on a few selected impact indicators mainly related to impacts induced by energy conversion [6]. As a result, more complex impact categories, such as toxicological impacts have not been given the same emphasis as the other more utilized and less uncertain impact categories, such as global warming potential. This also implies that life cycle inventory (LCI) analysis and life cycle impact assessment (LCIA) tools and models, and the data facilitating impact assessments induced by the elementary flows of chemicals with toxicological effects occurring over the long service lives and temporal scopes of buildings, have lagged behind the general development within LCI, LCA, and LCIA for the built environment. However, there have certainly been examples of LCA applied to the circular economy of building materials $[7,8]$ as well as efforts to introduce temporal issues such as non-linearity into characterization modeling [9].

Despite this, the general lack of representative tools, models, and data means that the human toxicological impacts induced by building materials during the use phase are often not accounted for, which is potentially problematic even in the assessment of a conventional linear economy, and can be seen in an analysis of typical LCIA methods applied in the built environment [10]. In a circular economy, where materials are reused-thus inhibiting the ability for current regulations for production to provide protections-the risk of exposing users to dangerous substances increases and should be assessed methodically. As pointed out by Eberhardt et al. [5], there is a major challenge in assessing environmental impacts in a circular economy with regard to allocating impacts from the initial production of a building component across all life cycles in which the building component is used. When it comes to the assessment of the toxicological impacts induced by a building component designed for the circular economy, the complexity of the assessment escalates. This is primarily because it is necessary to account for not only the distribution of the toxicological impacts induced by the initial production and subsequent life cycle stages including reuse and recycling, but also for the toxicity accumulated by the building material/component in one life cycle that can induce impacts in subsequent life cycles. For example, a concrete building component intended for the circular economy, which in its first life cycle was used in the garage of a single-family home where it was frequently exposed to fuels and solvents because the homeowner repaired cars, would have accumulated chemical residues over time. These chemical residues would remain in the concrete element once the house was dismantled, and if the building components were to be reused in new buildings, e.g., new single-family homes, then the residues could potentially induce toxicological impacts in subsequent use cycles.

Since LCA, and the accompanying LCI and LCIA tools and methodologies historically were developed for a linear economy, the challenges described above associated with a circular economy are known, however to a vast extent remain unquantified. Thus, in this article the authors seek to: (1) establish basic terminology for describing toxicological impacts associated with the circular economy within the built environment (2) quantitatively test the extent to which contemporary LCIA methodologies can be applied for the assessment of the human toxicological impacts of building materials/components in a circular economy, taking into considerations human toxicological impacts induced by the contamination of building materials, and (3) propose a best practice for the application of LCA in the assessment of the circular economy of buildings.

\section{Assessment of Toxicity}

The World Health Organization (WHO) estimated that 4.3 million deaths per year were attributable to household air pollution in 2012 [11]. Indoor sources of pollution include (among other sources) the combustion of fuels for heating and cooking, tobacco, radon, personal care products, furnishings, and building materials themselves. While the actions of inhabitants, and thus related emissions, are not likely to be included in the LCA of a building, the building materials should certainly be, however, in contemporary LCA, 
human health impacts originating from building materials during the use stage of buildings are most often not accounted for. This is truly problematic considering the number of deaths induced by indoor air pollution and the fact that toxic chemicals and materials, such as solvents, plasticizers, biocides, asbestos, heavy metals, and PCBs were frequently used in building materials in the past with some still being used in new construction today. As a first step in the direction of accounting for these issues, T. Ibn-Mohammed et al. [12] suggested a methodology for integrating human health impacts of building materials during the use stage in LCA, based on coupled near and far-field framework for determining a product intake fraction (PiF) complemented with an improved LCI.

In LCA, the toxicity of building materials/components is usually assessed as the toxicological impacts induced throughout the entire life cycle of the material from cradleto-grave, though other scopes are, of course, also somewhat common. This cradle-tograve way of assessing the toxicological impacts is methodologically similar to the carbon footprint methodology and is also referred to as the "embodied toxicity" or "toxicological footprint" [13] of a material/component and can be assessed using readily available LCA data and tools [14]. The toxicological footprint framework accounts for both impacts induced via direct exposure (i.e., through close contact with the building product being assessed) and indirect exposure (i.e., through impacts induced by background services, such as electricity production from manufacturing, etc.), as shown in Figure 1. In a circular economy, an additional assessment challenge accompanying the toxicological footprint is the quantification of the toxicological impacts induced by chemicals, which are contained, or rather that have become embedded within building materials at some point in the value chain. These chemicals can originate not only from the original production and manufacturing of the material/component (e.g., terpenes in wood or additives in concrete) but also from the accumulation of contamination during previous use(s) (e.g., the fuels and solvents in the concrete example presented earlier). These embedded chemicals are partially mobile and can be mobilized and emitted gradually or as pulses (i.e., under specific circumstances, such as high ambient temperatures, humidity, contact with other chemicals or materials including human skin, etc.) and induce toxicological impacts.

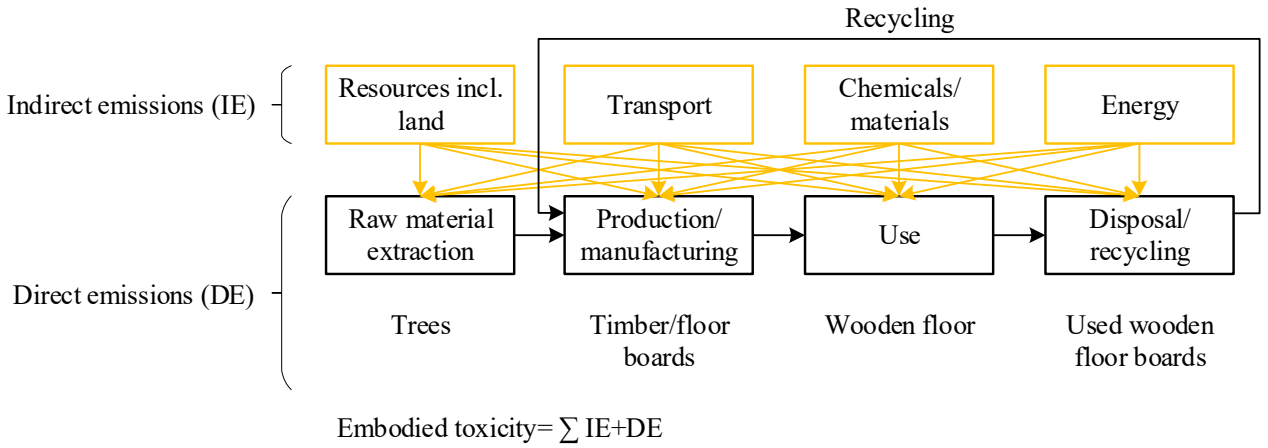

Figure 1. Visualization of the life cycle stages and emission types accounted for when calculating the toxicological footprint of wood.

In this article, we define the toxicological footprint as the overall emissions of substances that impact human health from building materials/components. These emissions, both direct and indirect, can be predicted by the proper accounting of all flows of toxic substances in the total life cycle of a material or product following a classical LCA approach. The term embedded toxicity is defined as the toxic substances contained in a product or material and which (presently only) can be quantified experimentally. The substances contributing to the embedded toxicity can originate from: (1) the initial product composition; (2) substances absorbed during cleaning and maintenance; (3) contamination, whether accidental or otherwise. As the embedded toxicity depends on the history of a material, it is always case-specific.

The toxicological footprint is important to assess, and LCA tools can and should be used for identifying the processes inducing the largest toxicological impact potential 
and improving them despite the limitations and associated uncertainties. The embedded toxicity is particularly relevant for evaluating the exposure during the use stage of a building, which is typically the longest stage in temporal terms, and for evaluating the suitability of material reuse in a circular economy. This embedded toxicity can be readily evaluated with experimental techniques.

T. Ibn-Mohammed et al. made a first attempt to account for chemicals embedded upstream in material/components during production and manufacturing and their toxicological impacts during the use stage of buildings, which is based on the actual chemical content of a product per functional unit (FU) [7]. This methodology, however, is not tailored to a circular economy as it only covers initial production, and hence, does not consider contamination during previous uses.

On a very general level, it is not possible to relate the magnitudes of the toxicological impact induced by the embodied and embedded chemical emissions since the toxicological impacts induced by these emissions are dependent on a multitude of parameters that include mass emitted, emission profile (pulse/continuous), exposure route, the toxicity of the chemical being emitted, etc. The toxicity of the chemicals emitted by a building material/component will, however, primarily be heavily correlated with the "history" of the building material/component and hence, dependent on both production circumstances and previous uses.

In this paper, we explore how to quantify the embedded toxicity and analyze casespecific relations between embodied and embedded toxicological impact potentials for two different building materials, wood, and concrete. These were selected due to their relative ubiquity in buildings and because they each respectively represent an organic or inorganic building material with great interest in regard to the circular economy in the built environment $[7,15]$.

\section{Methods}

\subsection{Introduction to Case Study}

This study explores two different cases of recycled building materials: wood and concrete. Both materials were randomly sampled from the building materials for recycling at the Danish recycling facility RGS Nordic A/S in Roskilde, Denmark. The embedded toxicity of the materials was experimentally assessed using a setup consisting of a temperatureinduced accelerated release of emitted chemicals from the building material samples in 250 mL DURAN ${ }^{\circledR}$ BlueCap flasks. The setup is intended to simulate an indoor environment situation with highly elevated temperatures. Among the chemicals emitted by the materials, the volatile organic compounds (VOCs) are extracted from the head space of the DURAN $^{\circledR}$ BlueCap flasks using the Solid Phase Micro Extraction (SPME) passive sampler, $50 \mu \mathrm{m} / 30 \mu \mathrm{m}$ divinylbenzene/Carboxen ${ }^{\circledR}$ on polydimethylsiloxane (DVB/CAR/PDMS) on an adsorbent StableFlex ${ }^{\mathrm{TM}}$ fiber [16].

The experimental setup applied represents a simplification and acceleration of an already existing and standardized laboratory testing method, in which material samples are analyzed for toxic substances such as VOCs, PCBs, metal, etc. The standardized test method involves 28 days of analysis in test chambers where the emitted substances are collected using passive samplers, such as Tenax ${ }^{\circledR}$ TA and 2,4-Dinitrophenylhydrazin (DNPH) tubes [17]. The simplified experimental setup used in our study is assumed to provide a representative scenario of the chemicals that can be emitted from a building material sample over a prolonged time horizon (centuries).

Because of the lack of representative empirical inventory data and models including emissions and embedding scenarios for building materials (including use), there is a possibility that the temperature-induced accelerated release of chemicals monitored in our study can yield emissions of toxic chemicals, which under "average real-world" circumstances would not have been emitted to the air compartment. It is thus considered important to keep in mind the explorative nature of this study and the fact that the results obtained from our analyzes should be seen more as a measure or test of how far LCA is from being 
capable of supporting circular economical related decisions rather than a quantitatively accurate evaluation of the toxicity embedded in building materials. Additionally, should generalization about embedded toxicity in the circular economy of building materials be desired, more extensive testing would be necessitated.

Materials, depending on their origin and previous uses, may contain complex mixtures of chemicals, some of which are naturally occurring. Whereas, other chemicals may occur in the material as a consequence of either intentional or unintentional incorporation into the material from exposure to chemicals during previous use. For instance, untreated wood contains complex mixtures of naturally occurring organic chemicals, such as acetic acid, formaldehyde, formic acid, and a variety of terpenes [18]. Preserved wood is of great environmental concern due to chemical treatment(s) prior to use [19], though in the case of Denmark, some of the impregnating agents containing creosote and arsenic have been banned by law in Denmark since 2006 [20]. Additionally, wood intended for outdoor use can be treated with waterproofing agents and fungicides, which can both contain chemical substances that are banned for indoor use in the EU [19], creating a hurdle in terms of eventual recycling and reuse of wood.

Toxic additives, such as aliphatic amines, dieldrin, various salts, and epoxide are frequently used in the production of concrete. The material itself also has the potential to absorb secondary hazardous chemicals during production and use, e.g., bitumen, chlorinated paraffin, phthalates, polychlorinated biphenyl (PCB), polycyclic aromatic hydrocarbons (PAH), as well as heavy metals such as mercury [21,22]. The Danish Environmental Protection Agency has, via extraction experiments from concrete, obtained data on the presence of various problematic chemicals, such as benzene, ethylene, naphthalene, toluene, xylene, and a variety of alkanes in concrete [21]. These chemicals contained in concrete represent a potential emission source of problematic chemicals from "circular" concrete products (i.e., concrete products containing recycled or reused concrete in various forms) or from crushed concrete, potentially resulting in a series of unwanted human health-related impacts if the crushed concrete is recycled into new building materials [23].

\subsection{Embedded Toxicity-Experimental Setup}

Recycled wood and concrete were collected, shredded and crushed, respectively, to fit into 250 mL DURAN ${ }^{\circledR}$ BlueCap flasks. A manual SPME holder was used to precondition the SPME fiber in the gas chromatography (GC) injector port for $0.5 \mathrm{~h}$ at $270{ }^{\circ} \mathrm{C}$ [16]. Triplicates of material batches were incubated at $70{ }^{\circ} \mathrm{C}$ for a total of $24 \mathrm{~h}$ in the $250 \mathrm{~mL}$ DURAN ${ }^{\circledR}$ BlueCap flasks equipped with septum caps following 30 min of SPME extraction of the head space/gaseous phase [16]. No considerable head space concentration changes were observed when prolonging incubation from $24 \mathrm{~h}$ to $48 \mathrm{~h}$, indicating that (air/concrete) equilibrium was reached within $24 \mathrm{~h}$, which was similarly observed by James and Yang [18]. The extracted analytes on the SPME fiber were desorbed into the GC injector port at $230{ }^{\circ} \mathrm{C}$ for qualitative and quantitative assessment in a gas chromatography-mass spectrometry (GC-MS) instrument with a DB-5MS capillary column (Dimensions: $30 \mathrm{~m}, 0.25 \mathrm{~mm}, 0.25 \mu \mathrm{m}$, 7 inches) [16]. The initial temperature of the GC oven was set to $30^{\circ} \mathrm{C}$, and the temperature was subsequently ramped at $5{ }^{\circ} \mathrm{C} / \mathrm{min}$ to $325^{\circ} \mathrm{C}$. The experimental setup is shown in Figure 2.

Data acquired from the MS detection was analyzed using the Xcalibur Qual Browser and the National Institute of Standards and Technology (NIST) Mass Spectral Library [24] to identify the different VOC analytes extracted from the materials. The chemicals were identified by comparing the spectrum of each peak in the chromatograms to reference spectra in the library [25]. Contamination tests of the flasks were performed using triplicates of a blank sample. Between each extraction, the SPME fibers were stored in glass vials and cleaned in the GC injector port to avoid further contaminations. VOCs emitted from the "clean" SPME fibers, the GC column, and the glassware was identified and quantified. The chemical equipment "contaminations" are listed in Table 1 and were subtracted from the results used in further analysis. 

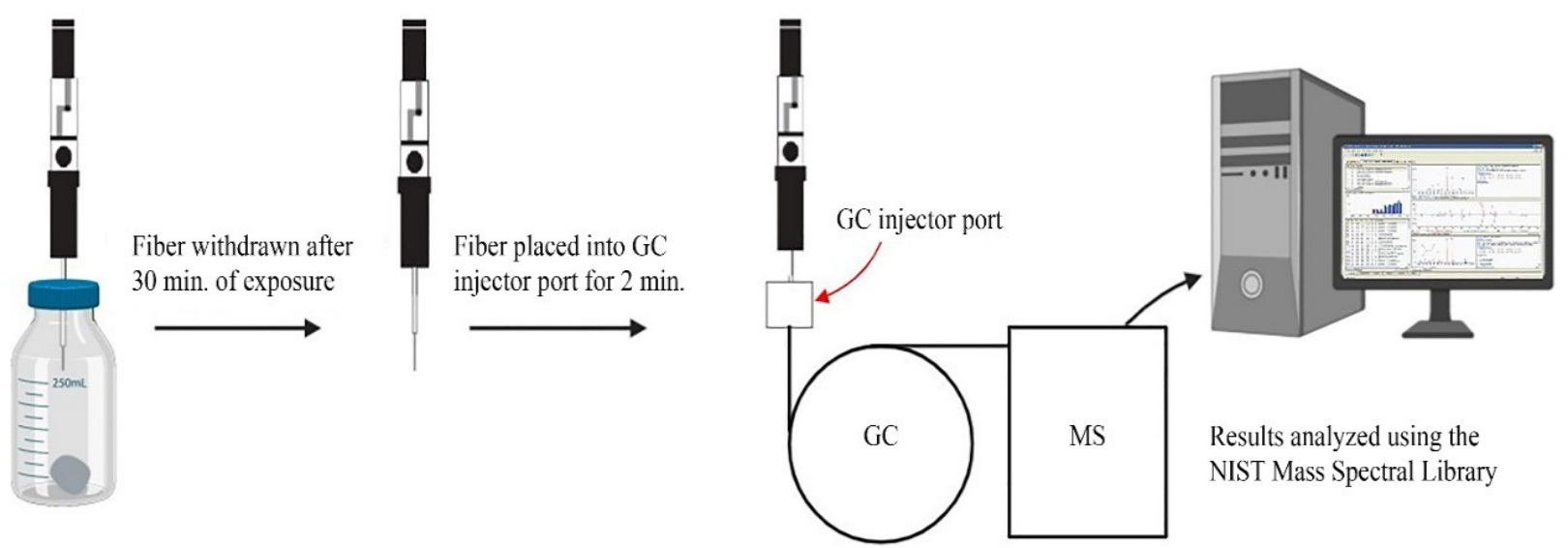

Figure 2. Experimental setup for analyzing the embedded toxicity of recycled wood and concrete. Samples are incubated at $70{ }^{\circ} \mathrm{C}$ for $24 \mathrm{~h}$ in 250 mL DURAN ${ }^{\circledR}$ BlueCap flasks with septum caps. After the incubation, the solid-phase microextraction (SPME) fiber is exposed to the gaseous phase inside the flask for $30 \mathrm{~min}$ before being injected into the gas chromatography (GC) injector port for $2 \mathrm{~min}$ desorption at $230{ }^{\circ} \mathrm{C}$. The injected sample runs through the gas chromatography-mass spectrometry (GC-MS) instrument for $60 \mathrm{~min}$ to separate, detect, and analyze the sample giving a full CG-MS chromatogram with the substances in the sample. The substances emitted from each sample can be qualitatively identified using the Xcalibur Qual Browser and the National Institute of Standards and Technology (NIST) Mass Spectral Library.

Table 1. VOCs were identified from the contamination test of the SPME fiber and the GC-MS column itself, as well as the blank samples. The compound is identified with a CAS number (CAS no.) from the National Institute of Standards and Technology (NIST) library. However, a CAS no. was not available (N/A) for the various types of cyclosiloxane.

\begin{tabular}{cc}
\hline Compound & CAS No. \\
\hline 1-(2,3-dimethyl-furan-3-yl)ethanone & $10599-70-9$ \\
1-Hexanol & $111-27-3$ \\
2,3-Dihydroxypropylelaidate & $25496-72-4$ \\
Dodecane & $112-40-3$ \\
Dronabinol & $1972-08-3$ \\
Hexadecanoic acid & $10499-94-2$ \\
Octadecanoic acid & $57-11-4$ \\
Octane & $111-65-9$ \\
Oleic acid & $112-80-1$ \\
Oxime (Acetophenone) & $613-91-2$ \\
Pentadecanoic acid & $1002-84-2$ \\
Phenol & $108-95-2$ \\
Propanoic acid & $79-09-4$ \\
Toluene & $108-88-3$ \\
Cyclosiloxane & N/A \\
\hline
\end{tabular}

Therefore, if emitted by a material sample, these VOCs would not be included in further analysis and are thus subtracted from the results. The subtracted "contaminations" included for concrete is toluene; and for both wood and concrete, they include oleic acid, propanoic acid, and various types of cyclosiloxane that were identified.

The areas under the identified peaks from the chromatograms were used in the quantification of the chemical compounds emitted from the material samples along with a standard curve of hexane $(0.5 \mathrm{ppm}, 1 \mathrm{ppm}, 2 \mathrm{ppm}, 4 \mathrm{ppm}, 8 \mathrm{ppm}, 16 \mathrm{ppm})$ providing a conversion factor and reference for the concentration (unit $\mathrm{ppm}_{\mathrm{m}}$ or $\mathrm{mg} / \mathrm{kg}$ ) of chemicals emitted from the samples analyzed [26,27]. Quantitative data of the chemicals emitted by the material samples (unit $\mathrm{ppm}_{\mathrm{m}}$ ) was used in combination with characterization factors 
from the International Reference Life Cycle Data System (ILCD) 2.02018 midpoint [28] and the USEtox 2.12 [29] model [30] to quantify the human toxicological impact potentials of the chemicals identified and quantified in the experimental setup.

The chosen impact categories were carcinogenic and non-carcinogenic toxicological impacts on human health induced by chemicals emitted into the air in both low and high population density areas. The low and high population density elementary flows were chosen to assess the fraction of humans exposed when the chemical is emitted to the environment (i.e., air) in peri-urban/rural and urban areas. The characterization factors for the human toxicological midpoint impact potential are from USEtox 2.12 [29] and ILCD 2.0 [28], provided in the unit CTUh (comparative toxic unit for human per kg elementary flow) [30]. Subsequently, the human toxicological impact potentials were converted from CTUh to DALY (disability-adjusted life years) using weighting factors (11.5 for carcinogenic effects and 2.7 for non-carcinogenic effects) in accordance with [31-33].

\subsection{Toxicological Footprint}

The toxicological footprint corresponding to the toxicological impact potential induced throughout the whole life cycle of concrete and wood was assessed using the OpenLCA 1.10.3 [34] product system modeling software along with the Ecoinvent v.3.6 inventory database [35]. The toxicological footprint was assessed by relying on the ILCD 2.02018 midpoint impact category "human toxicological impact" in accordance with the consequential system boundary approach as the basis for LCI analysis [14]. The human toxicological impacts were assessed as either carcinogenic or non-carcinogenic effects in the unit DALY. The human toxicological impact potential was subsequently assessed by applying a FU corresponding to a $1 \mathrm{~m}^{2}$ concrete or wood surface with a thickness of $150 \mathrm{~mm}$ during its whole life cycle from production to end-of-life (EOL). In this case, the only EOL option considered was the recycling of building materials. To enable the comparison of the embodied and embedded toxicity, the LCAs of $1 \mathrm{~kg}$ of wood and concrete, respectively, were carried out.

The life cycles of recycled wood and concrete were then modeled based on the system boundaries indicated in Figure 3, covering all relevant processes needed for raw material extraction, manufacturing, production, transport, and EOL. The maintenance of recycled wood or concrete was neglected, and the "use" stage was excluded. If paint or other treatments had been included, then they would also have contributed to the toxicological impacts on human health embedded in the material samples. However, records on the history of the concrete and wood samples collected are not available due to the mixed provenance of the waste stream. The recycling of wood or concrete from building materials was also modeled to avoid the impact of specific processes, including the production of wood or concrete for new building materials.

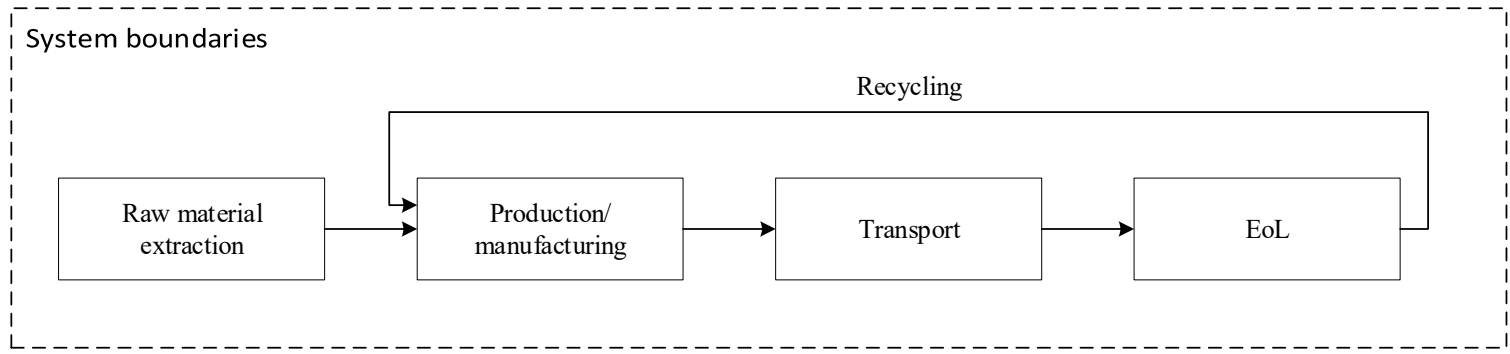

Figure 3. Basic system boundaries are applied for modeling the embodied toxicity throughout the whole life cycle of recycled wood and concrete. All processes needed for the raw material extraction, manufacturing/production, transportation, and end-of-life (EOL) stages are included in the modeled system.

Concrete production involves processes needed for the extraction of raw materials, such as sand, gravel, stone, Portland cement, energy, and water. It is assumed that the ready-mixed concrete is transported for a maximum of $100 \mathrm{~km}$ (thus avoiding the hardening 
of concrete during transport). The EOL scenario involves the concrete being crushed and recycled on-site, e.g., as a replacement for gravel in the production of new concrete.

The production of wooden building materials involves the occupation of arable land as well as raw materials, such as seeds, water, fertilizer, and energy. It is assumed, that the wood is produced in Denmark, and thus the transportation of wood was limited to $100 \mathrm{~km}$. While wood could be produced elsewhere, long-distance transport (by rail or ship) is not typically a large contributor toward impacting its life cycle. The EOL scenario involves recycling the wood into new wooden building materials.

\section{Results}

\subsection{Embedded Toxicity}

The experimental setup yielded data that revealed a release of 9 substances from the recycled concrete samples and 10 substances released from the recycled wood samples. As presented in Tables 2 and 3, all chemicals released from concrete can be categorized as having been absorbed by and embedded in the concrete at some point along its value chain, since these chemicals are not naturally found in concrete [21]. The majority of chemicals released from wood are naturally occurring in the material apart from naphthalene and cyclohexene. Chemicals categorized as naturally occurring in wood can however also potentially affect human health. For instance, chronic exposure to hexanal, which is found in wood, can lead to organ impacts and failure [36]. Sources that contribute to the intentional or unintentional contamination of the wood with chemicals in the materials could include paints and other surface treatments during use cycles.

Due to the low availability of chemical-specific human toxicological characterization factors in the most recent (at the time of calculation) version of USEtox 2.12 [30] and ILCD 2.02018 midpoint [28] characterization methods, it was only possible to characterize 5 of the 18 identified chemical compounds emitted from the material samples. These chemical compounds are benzene, benzaldehyde, hexane, naphthalene, and pyridine as shown in Table 4. These are marked with an * in Tables 2 and 3.

Table 2. Identified VOCs emitted from three samples of recycled wood, categorized with CAS no., origin ( $\mathrm{N}=$ naturally occurring $/ \mathrm{I}=$ incorporated chemical) and concentration in $\mathrm{ppm}_{\mathrm{m}} \cdot{ }^{*}$ denotes the chemicals for which characterization factors exist.

\begin{tabular}{|c|c|c|c|c|c|}
\hline \multirow{2}{*}{ VOC Emitted } & \multirow{2}{*}{ CAS No. } & \multirow[t]{2}{*}{ N/I } & \multicolumn{3}{|c|}{$\begin{array}{l}\text { Sample Specific Concentrations } \\
\left(\mathrm{ppm}_{\mathrm{m}}\right)\end{array}$} \\
\hline & & & 1 & 2 & 3 \\
\hline 2-Norpinene, 3,6,6-trimethyl & $4889-83-2$ & $\mathrm{~N}$ & 1286.3 & 399.92 & 904.27 \\
\hline 3-carene & $13466-78-9$ & $\mathrm{~N}$ & 71.67 & - & 33.34 \\
\hline$\alpha$-Longipinene & $5989-08-2$ & $\mathrm{~N}$ & - & - & 109.60 \\
\hline$\alpha$-Pinene & $80-56-8$ & $\mathrm{~N}$ & 841.04 & 91.90 & 458.58 \\
\hline$\alpha$-Terpinene & $99-86-5$ & $\mathrm{~N}$ & 122.33 & - & - \\
\hline$\alpha$-Terpineol & $98-55-5$ & $\mathrm{~N}$ & 708.02 & - & - \\
\hline Bornylacetate & $5655-61-8$ & $\mathrm{~N}$ & - & - & 20.26 \\
\hline Cyclohexene & $110-83-8$ & $\mathrm{I}$ & 767.47 & - & 493.94 \\
\hline Hexanal & $66-25-1$ & $\mathrm{~N}$ & - & 50.21 & 34.63 \\
\hline Naphthalene * & $91-20-3$ & I & 76.98 & - & 287.87 \\
\hline
\end{tabular}


Table 3. Identified VOCs emitted from 10 samples of recycled concrete, with CAS no., origin $\left(\mathrm{N}=\right.$ naturally occurring $/ \mathrm{I}=$ incorporated chemical) and concentration in $\mathrm{ppm}_{\mathrm{m}}$. ${ }^{*}$ denotes the characterized chemicals.

\begin{tabular}{|c|c|c|c|c|c|c|c|c|c|c|c|c|}
\hline \multirow{2}{*}{ VOC Emitted } & \multirow{2}{*}{ CAS No. } & \multirow{2}{*}{ N/I } & \multicolumn{10}{|c|}{$\begin{array}{l}\text { Sample Specific Concentrations } \\
\left(\mathrm{ppm}_{\mathrm{m}} \text { Material) }\right.\end{array}$} \\
\hline & & & 1 & 2 & 3 & 4 & 5 & 6 & 7 & 8 & 9 & 10 \\
\hline 1-Heptene & $592-76-7$ & I & - & 3.69 & 9.70 & 299.64 & 16.53 & 5.71 & 3.66 & 3.28 & 3.71 & 19.77 \\
\hline 2,4-Hexadieneoic acid & $110-44-1$ & I & - & 4.94 & - & - & - & - & - & - & - & - \\
\hline 3-Heptene-2,6-dione & $99809-46-8$ & I & - & 6.20 & - & - & - & - & - & - & - & - \\
\hline Benzaldehyde * & $100-52-7$ & I & 99.25 & - & - & 62.50 & 6.07 & 22.44 & 33.51 & 27.34 & 2.35 & 1.44 \\
\hline Benzene * & $71-43-2$ & I & 21.95 & 22.95 & 19.19 & 13.35 & 27.50 & 14.76 & 8.21 & 9.47 & 1.91 & 0.80 \\
\hline Decane & $124-18-5$ & I & 1663.3 & 93.01 & 360.91 & 171.70 & 42.39 & 232.90 & 45.00 & 179.29 & 3.41 & 14.21 \\
\hline Hexane * & $110-54-3$ & I & - & 1.26 & - & - & - & - & - & - & - & - \\
\hline Naphthalene * & $91-20-3$ & I & - & - & 26.41 & 188.35 & 26.07 & 81.88 & - & - & 8.86 & - \\
\hline Pyridine * & $110-86-1$ & $\mathrm{I}$ & 41.01 & - & - & - & - & - & - & - & - & - \\
\hline
\end{tabular}

Table 4. Characterization factors for benzaldehyde, benzene, hexane, naphthalene, and pyridine were given in CTUh and converted to DALY using weighting factors 11.5 and 2.7 for carcinogenic and non-carcinogenic effects, respectively. $\mathrm{LPD}=$ Low population density, HPD $=$ High population density, $\mathrm{C}=$ Carcinogenic effects and $\mathrm{NC}=$ Non-carcinogenic effects. The reference database for the characterization factors is marked with A = ILCD database [28] and B = USEtox database [30] only.

\begin{tabular}{|c|c|c|c|c|c|c|c|}
\hline \multirow[b]{2}{*}{ Chemical Name } & \multicolumn{5}{|c|}{ Characterization Factors } & \multirow[b]{2}{*}{ Naphthalene } & \multirow[b]{2}{*}{ Pyridine } \\
\hline & & & Benzaldehyde & Benzene & Hexane & & \\
\hline CAS No & & & $100-52-7$ & $71-43-2$ & $110-54-3$ & $91-20-3$ & $110-86-1$ \\
\hline \multirow{4}{*}{$\begin{array}{c}\text { ILCD }^{A} / \text { USEtox }^{B} \\
\text { (CTUh per kg material) }\end{array}$} & \multirow{2}{*}{ LPD } & $\mathrm{C}$ & $2.21 \times 10^{-9} \mathrm{~A}$ & $1.20 \times 10^{-7 \mathrm{~A}}$ & $1.93 \times 10^{-10 \mathrm{~A}}$ & $6.35 \times 10^{-7 \mathrm{~A}}$ & $5.40 \times 10^{-7 B}$ \\
\hline & & $\mathrm{NC}$ & $2.87 \times 10^{-9} \mathrm{~A}$ & $3.04 \times 10^{-8 \mathrm{~A}}$ & $2.62 \times 10^{-8 \mathrm{~A}}$ & $8.74 \times 10^{-7} \mathrm{~A}$ & $1.64 \times 10^{-6 B}$ \\
\hline & \multirow{2}{*}{ HPD } & $\mathrm{C}$ & $3.39 \times 10^{-8 \mathrm{~A}}$ & $4.74 \times 10^{-7} \mathrm{~A}$ & $1.79 \times 10^{-9} \mathrm{~A}$ & $1.22 \times 10^{-6 \mathrm{~A}}$ & $2.84 \times 10^{-6 B}$ \\
\hline & & $\mathrm{NC}$ & $4.40 \times 10^{-8 \mathrm{~A}}$ & $1.20 \times 10^{-7 \mathrm{~A}}$ & $2.44 \times 10^{-7 \mathrm{~A}}$ & $1.68 \times 10^{-6 \mathrm{~A}}$ & $8.62 \times 10^{-6 B}$ \\
\hline \multirow{4}{*}{$\begin{array}{c}\text { ILCD }^{\text {A }} / \text { USEtox }^{B} \\
\text { (DALY per kg } \\
\text { material) }\end{array}$} & \multirow{2}{*}{ LPD } & $\mathrm{C}$ & $2.54 \times 10^{-8 \mathrm{~A}}$ & $1.38 \times 10^{-6 \mathrm{~A}}$ & $2.22 \times 10^{-9} \mathrm{~A}$ & $7.30 \times 10^{-6 \mathrm{~A}}$ & $6.21 \times 10^{-6 B}$ \\
\hline & & $\mathrm{NC}$ & $7.75 \times 10^{-9} \mathrm{~A}$ & $8.21 \times 10^{-8 \mathrm{~A}}$ & $7.07 \times 10^{-8 \mathrm{~A}}$ & $2.36 \times 10^{-6 \mathrm{~A}}$ & $4.43 \times 10^{-6 B}$ \\
\hline & \multirow{2}{*}{ HPD } & $\mathrm{C}$ & $3.90 \times 10^{-7 \mathrm{~A}}$ & $5.45 \times 10^{-6 \mathrm{~A}}$ & $2.06 \times 10^{-8 \mathrm{~A}}$ & $1.40 \times 10^{-5 \mathrm{~A}}$ & $3.26 \times 10^{-5 B}$ \\
\hline & & $\mathrm{NC}$ & $1.19 \times 10^{-7 \mathrm{~A}}$ & $3.24 \times^{-7 \mathrm{~A}}$ & $6.59 \times 10^{-7 \mathrm{~A}}$ & $4.55 \times 10^{-6 \mathrm{~A}}$ & $2.33 \times 10-5^{B}$ \\
\hline
\end{tabular}

As presented in Tables 2 and 3, the concentration variations observed between the samples are considerable, which also causes the average embedded human toxicity impact per $\mathrm{kg}$ building material sample to exhibit significant variations. Figure 4 provides an illustration of the difference between the highest and lowest toxicity impact per $\mathrm{kg}$ of concrete and wood. Only a small variation is observed for the human toxicological impacts induced by $1 \mathrm{~kg}$ of the wood samples. One could postulate that this was a result of the surface properties of wood, relative to e.g., concrete, but it could just as easily be another property or simply the happenstance of sampling that resulted in this lower level of variation. Additionally, this could have resulted from the low percentage of total chemicals able to be characterized. Regardless, more testing would be required to arrive at a conclusion regarding this relative lack of variation. 


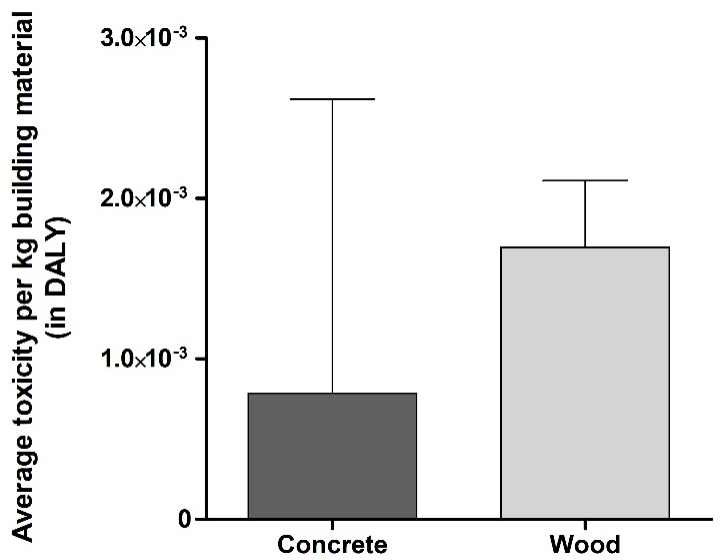

Figure 4. The average embedded toxicity impact per kg building material is given in DALY with a standard deviation. The standard deviation for the average embedded toxicity impact of concrete is very large compared to that of wood, which is due to the large impact variation between the samples of concrete.

Figure 5 indicates the mass share of chemicals per $\mathrm{kg}$ material that could be characterized relative to the total amount of identified chemicals. In $1 \mathrm{~kg}$ of concrete, it was possible to characterize on average $45 \%$ of the chemicals: $21 \%$ naphthalene, $13 \%$ benzaldehyde, $10 \%$ benzene, $1 \%$ hexane, and $<1 \%$ pyridine. The reason why more naphthalene is extracted from concrete compared to the other chemicals could be twofold. First, naphthalene is less volatile compared to e.g., benzene, which is indicated by the vapor pressures and Henry's law constants [37] of the two compounds (please see Appendix A Tables A1 and A2). The low volatility causes naphthalene to remain "trapped" and persists longer in the building materials analyzed relative to more-volatile compounds like benzene. Secondly, the elevated temperature applied during the thermal stripping of materials may have resulted in a naphthalene (burst) release. In $1 \mathrm{~kg}$ of wood, only naphthalene could be characterized using the available characterization factors, representing on average only $4 \%$ of the chemicals detected in wood. For both wood and concrete, the fraction of chemicals identified and quantified in the experimental setup that could not be characterized is considerable. This non-characterizable fraction of chemicals could play a decisive role when assessing the toxicity of building materials since these chemicals cannot be accounted for and thus, apart from a potential direct accounting of mass with relation to the impact assessment, are disregarded.

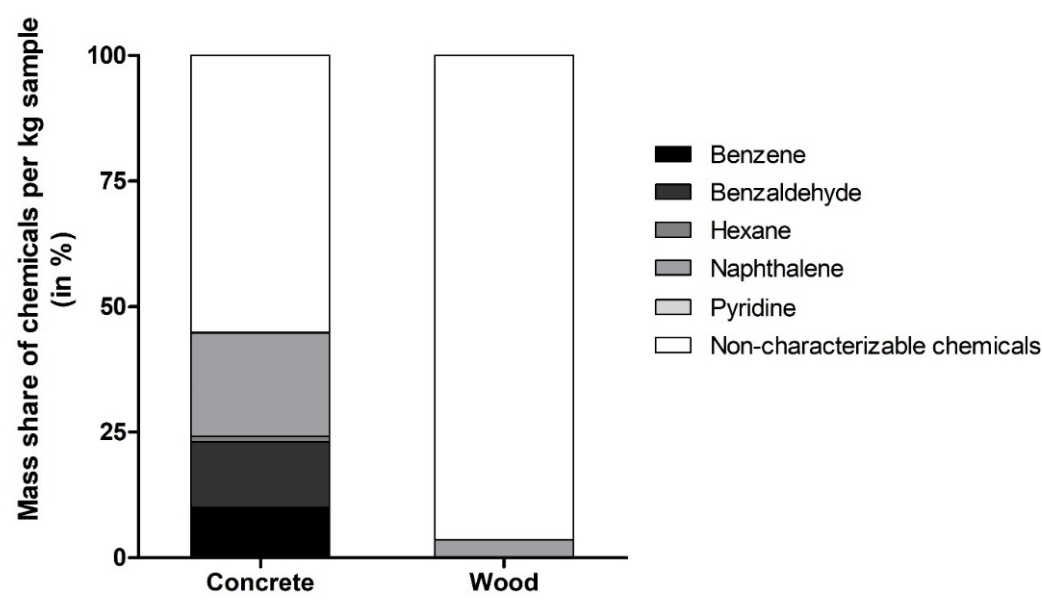

Figure 5. The average mass share (in \%) of identified and characterized chemicals per $\mathrm{kg}$ building material. In concrete, $45 \%$ of the identified chemicals could be characterized, including $21 \%$ naphthalene, $13 \%$ benzaldehyde, $10 \%$ benzene, $1 \%$ hexane and $<1 \%$ pyridine. In the wood samples, only naphthalene could be characterized, which comprised $4 \%$ of the identified chemicals. 


\subsection{Toxicological Footprint}

The system inventory data acquired from the assessment of the system was converted into the midpoint category "human toxicity" using OpenLCA [38], and the human toxicity impact potential per FU was, as presented in Figure 6, divided into carcinogenic and non-carcinogenic effects.

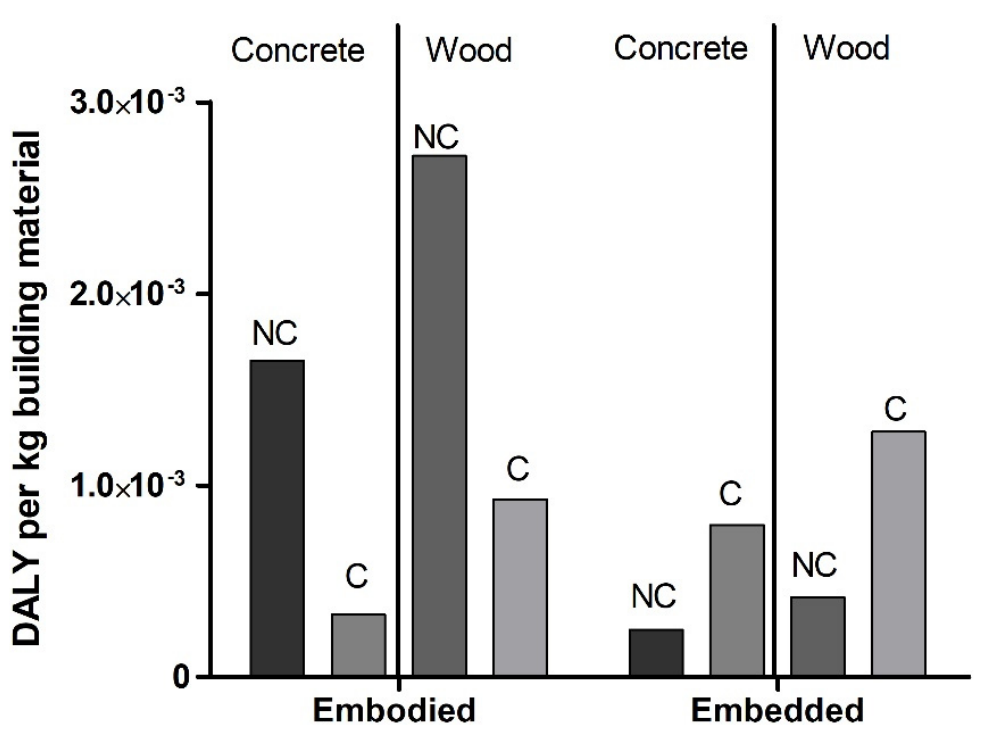

Figure 6. The initial embodied and embedded human toxicity impact given for carcinogenic $(\mathrm{C})$ and non-carcinogenic (NC) effects in DALY per $\mathrm{kg}$ of building material. The initial embodied and embedded human toxicity impact is separated between concrete and wood. The initial embedded and embodied impact is provided in $\mathrm{kg}$ which cannot be translated into a construction context.

The modeled product system for $1 \mathrm{~kg}$ of concrete involves the following inputs in OpenLCA: the Swiss market for "gravel, crushed" $(0.432 \mathrm{~kg})$ to model crushed gravel; the Europe without Switzerland market for "cement, Portland" $(0.0874 \mathrm{~kg})$ to model Portland cement; the Danish "gravel and sand operation" $(0.396 \mathrm{~kg})$ for sand; the global market for "lubricating oil" $\left(5.1 \times 10^{-6} \mathrm{~kg}\right)$ as well as water $(0.0685 \mathrm{~kg})$ as an elementary flow. All values for the production of concrete are taken from the Ecoinvent Database process "concrete production $20 \mathrm{MPa}$ " [35]. Transportation of ready-mixed concrete is modeled using the European "transport, freight, lorry 16-32 metric ton" (0.1 t. km). The concrete is recycled on the demolition site to gravel using a crushing machine, which is modeled using the global market for "diesel burned in building machine" (0.0437 MJ) [35]. The avoided production of gravel is modeled using the Swiss market for "gravel, crushed" $(-1 \mathrm{~kg})$ [35].

The product system for $1 \mathrm{~kg}$ of wood is modeled using the following inputs in OpenLCA: the European market for "sawnwood, softwood, dried $(\mathrm{u}=10 \%)$, planed" (1 kg); the European market for "transport, freight, lorry 16-32 metric ton" (0.1 t. km); and the Swiss process "treatment of waste wood, post-consumer, sorting and shredding" $(0.2 \mathrm{~kg})$ along with the avoided production of wood pellets $(-0.8 \mathrm{~kg})$ [35].

Data from Figure 6 shows that $1 \mathrm{~kg}$ of wood has a higher embodied human toxicity impact than $1 \mathrm{~kg}$ of concrete regarding both carcinogenic and non-carcinogenic effects. The greatest impact contribution from $1 \mathrm{~kg}$ of wood comes from the production of wood. The avoided processes associated with wood production are accounted for when the wood is recycled into new wooden materials. The embedded toxicological impact potential in terms of carcinogenic effects is greater than the non-carcinogenic impact potential, which is the inverse pattern of the toxicological footprint. The impact of carcinogenic effects from the embedded toxicity is also larger than the toxicological footprint, while the impacts of non-carcinogenic effects are highest for the toxicological footprint. 
The average embedded human toxicity and the embodied human toxicity were compared by calculating toxicity equivalency between the two impact results. The toxicity equivalency is defined as the embedded toxicity per $\mathrm{kg}$ of material needed to match the toxicological footprint per $\mathrm{kg}$ of material. This is shown in Table 5, which indicates that to reach a break-even point between embodied and embedded toxicity per $\mathrm{kg}$ of material, $1.91 \mathrm{~kg}$ of concrete or $2.15 \mathrm{~kg}$ wood is needed, respectively.

Table 5. Comparison of the average embedded toxicity in DALY per kg material and the embodied toxicity (toxicological footprint) in DALY per kg material given as a toxicity ratio (Embodied:Embedded).

\begin{tabular}{ccc}
\hline & Concrete & Wood \\
\hline Average embedded human toxicity (DALY per kg material) & $1.04 \times 10^{-3}$ & $1.70 \times 10^{-3}$ \\
\hline Embodied human toxicity (DALY per kg material) & $1.98 \times 10^{-3}$ & $3.64 \times 10^{-3}$ \\
\hline Toxicity equivalency (Embodied:Embedded) & $1: 1.91$ & $1: 2.15$ \\
\hline
\end{tabular}

The data in Figure 6 is provided as the impact per $\mathrm{kg}$ of material, which is not so easily translatable for construction purposes. Therefore, the toxicological footprint impact per $\mathrm{m}^{2}$ with a specified thickness of $150 \mathrm{~mm}$ was also calculated using the impact per $\mathrm{kg}$ of material and the density of the material.

First, Figure 7 illustrates that the human toxicological impact of carcinogenic and non-carcinogenic effects from the embodied human toxicity of $1 \mathrm{~m}^{2}$ concrete is greater than the embodied impact of $1 \mathrm{~m}^{2}$ wood. The impact assessment conducted per $\mathrm{m}^{2}$ of material provides a different outcome than the impact per $\mathrm{kg}$ of material, which is due to the different densities of the materials. The concrete is assessed assuming a density of $2350 \mathrm{~kg} / \mathrm{m}^{3}$ while the wood is assessed assuming a density of $650 \mathrm{~kg} / \mathrm{m}^{3}$. This results in the impact of non-carcinogenic impact potentials per $\mathrm{m}^{2}$ of concrete being approximately 2-3 times larger than the impact potential per $\mathrm{m}^{2}$ wood. As observed for the results reported on a per mass basis (see Figure 7), the embedded toxicity impact potential in terms of carcinogenic effects is larger than the embedded toxicity impact potential in terms of non-carcinogenic effects, while also being larger than the embodied toxicity impact potential of carcinogenic effects.

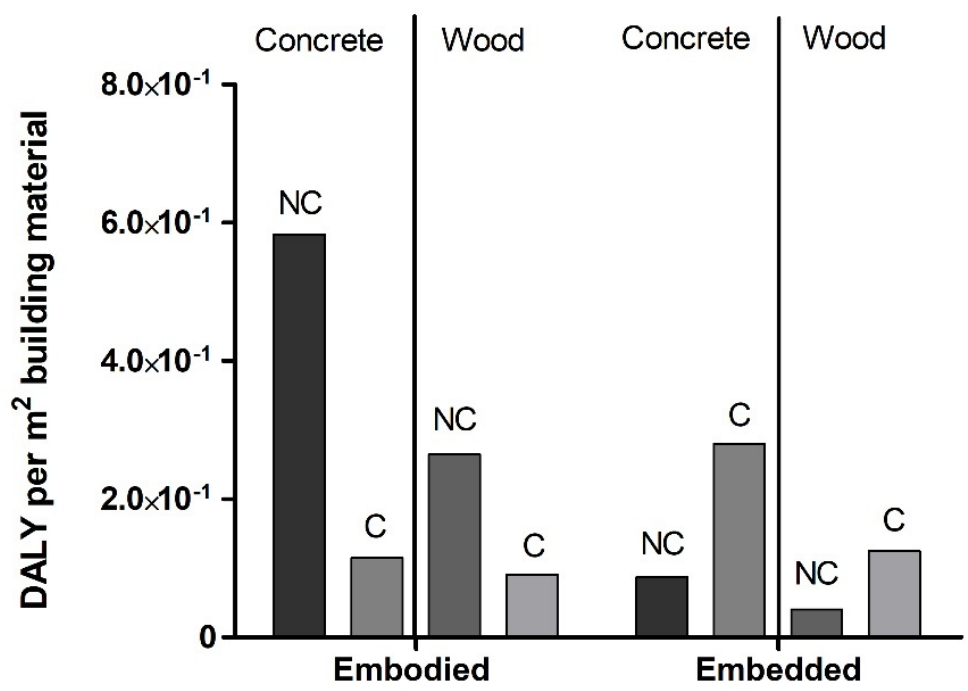

Figure 7. The final embodied and embedded human toxicity impact given for carcinogenic (C) and non-carcinogenic (NC) effects in DALY per $\mathrm{m}^{2}$ building material. The final embodied and embedded human toxicity impact is separated between concrete and wood. The impact per $\mathrm{m}^{2}$ wood and concrete are used for the comparison and selection of building materials in a real-world construction context. 


\section{Discussion}

In the context of LCA, building materials represent a unique set of challenges, which primarily stem from the original development of LCA as a method to compare products with a short service life, such as packaging and energy [1,2]. In comparison, buildings last for centuries and are hence, in terms of service life, different from many conventional commodities. Considering the exceptionally long service life of buildings, and that humans spend approximately 90\% [39] of their lives indoors, there is a resultant large potential for human exposure to substances emitted from buildings. Furthermore, the circular economy adds further complexity to the LCA of buildings, since the service lives of materials, components, and whole structures are extended beyond their already long service lives. In addition to magnifying the known issues of building LCAs, the circular economy adds a whole new set of complexities to LCA when it comes to the migration of contaminants within the value chain.

The toxicological footprint is a conventional assessment already applied for other impact indicators. However, in order to quantify toxicological effects in circular economic models, the authors find it necessary to differentiate between embodied and embedded toxicological impacts both for the sake of further development of LC(I)A and for the sake of building designers. By further qualifying the toxicological footprint assessment by differentiating between embodied and embedded toxicological impacts of buildings, communication of toxicological assessments of circular economic models for the built environment can become more manageable and mitigation measures more obvious and focused.

\subsection{Uncertainty in the Assessment Method}

The embedded toxicity of building materials has been assessed in this paper using an accelerated release of emission from recycled wood and concrete. As a result of this assessment, it was possible to identify chemicals that were present in the material samples that potentially could be released under realistic meteorological conditions to either indoor air or ambient air in high and low population areas. There is a potential that the approach applied in this paper yields overestimations of emissions from the materials since some VOCs might not be released from the materials under conventional room temperatures.

The results are vastly dependent on the ability of the VOCs in the materials to volatilize during thermal stripping $\left(70{ }^{\circ} \mathrm{C}\right.$ in the present case). Furthermore, the VOCs found in the gaseous equilibrium phase of the $250 \mathrm{~mL}$ DURAN ${ }^{\circledR}$ BlueCap flasks are selectively extracted by the SPME fiber in accordance with their affinity to interact with the chosen coating of the SPME fiber. The DVB/CAR/PDMS coating is chosen because of its high specificity towards VOCs, however, some VOCs can have a higher binding affinity to the coating compared to other VOCs. This means that if the samples contained chemicals with low vapor pressure and/or affinity for the SPME fibers, these may not have been detected.

\subsection{Qualitative Results}

All chemicals detected in the concrete samples were categorized as embedded into the material at some point in the value chain of concrete, while most chemicals identified in the wood samples are naturally occurring and hence stem from the production of the wood. The non-natural chemicals embedded in wood and concrete are most likely pollutants coming from paints, lacquers, or other materials used during maintenance, indicating that a considerable fraction of the chemicals detected were emitted from other sources and absorbed into the materials.

It is striking that characterization factors for quantification of human toxicological impact potentials have only been identified for 5 out of the 18 chemicals identified during the experimental analyzes developed for assessing embedded toxicity. Of the identified chemicals, characterization factors currently only exist for benzaldehyde, benzene, hexane, naphthalene, and pyridine while they are missing for 2-norpinene, 3,6,6trimethyl-3-carene, 
$\alpha$-longipinene, $\alpha$-pinene, $\alpha$-terpinene, $\alpha$-terpineol, bornylacetate, cyclohexene, hexanal, 1-heptene, 2,4-hexadieneoic acid, 3-heptene-2, 6-dione, and decane.

Of those chemicals, benzene is classified by the IARC as group 1 (carcinogenic to humans) and naphthalene and pyridine as group 2B (possibly carcinogenic to humans) [40]. Three of these chemicals have also been frequently observed in indoor air in residences. Among the 18 identified substances, naphthalene has been frequently monitored with representative concentrations in the indoor air of $0.1-1 \mu \mathrm{g} / \mathrm{m}^{3}$; this is also the case for benzene and hexane with representative concentrations in the indoor air of $1-10 \mu \mathrm{g} / \mathrm{m}^{3}$ [41]

The subtraction of chemical analytical equipment 'contaminations' from the results could potentially have led to invalid and much larger embedded toxicological impact potentials of the building materials. This issue was especially pronounced for concrete, where toluene was found in one of the samples. Toluene can be characterized using available characterization factors, which indicate that it is a chemical capable of inducing toxicological impacts and hence adverse effects on human health upon exposure. If toluene was not subtracted from the results, the embedded toxicity impact of concrete would appear to be even higher.

For concrete, $45 \%$ of the identified chemicals could be characterized, while for wood only $4 \%$ could be characterized. This is a clear demonstration that extensive development of additional characterization factors is necessary for providing a more complete and meaningful assessment of human toxicity. It also indicates that the current state of development is not satisfactory when it comes to assessing circular economic models. The low fraction of characterizable chemicals also leads to the questions: can it be anticipated that further characterization factors will be developed in the short-term, and is this task too challenging, considering the 21,551 [42] chemical substances registered for use in the EU? In the Pharos database, developed by the Healthy Building Network [43], 756 chemicals have been identified in building materials, 184 of which were present in USEtox and 67 of which were associated with human toxicity effect factors [12]. Further, considering the uncertainties of inventory and exposure models needed for appropriate assessment of toxicological impacts induced via the circular economy and the need to assess toxicological impacts in a uniform manner irrespective of origin, it is considered relevant to assess (and validate) if the current characterization paradigm applied in LCA is appropriate and relevant, or if characterization (of toxicological impacts) could be made more effective.

It is also considered important that, even though the embedded toxicity of only $4 \%$ of the identified chemicals in wood could be assessed, the embedded potential carcinogenic impacts of wood are greater than the embodied equivalent. Since the embedded toxicity also includes accidental additions to the toxicological footprint through contaminants absorbed during the use phase by a building material or component, cases could occur where excessive contaminations would yield embedded toxicological impacts exceeding embodied toxicological impacts. However, especially in the case of the analyzed wood samples for which only naphthalene was considered not from natural origin, this observation can also indicate the lack of precision of the current LCA methodologies and models for assessing human toxicity.

The models needed for accounting for toxicological impacts in relation to a circular economy are very complex and rely on the (further) development of (1) Inventory models and data capable of accounting for the migration of chemical compounds in (circular) value chains (i.e., chemical migration inside the technosphere), (2) fate models (for estimating the dissipation of a chemical substance in the (indoor and outdoor environment) supporting both the inventory and characterization models), and (3) exposure/characterization models (to estimate the population exposure to a chemical substance under various building use situations) [30]. Each of these models is associated with considerable uncertainties and the final result of the estimation of the human toxicity of a building material/component used in the circular economy is inherently also accompanied by an even higher uncertainty [5].

Considering that the human indoor exposure during the use phase of a building material/component is only rarely taken into account no matter what LCA methodology 
applied, our results indicate that this omission should be a priority with regard to future research, as the use phase has the potential to contribute significantly to the total human toxicological impacts of these building materials. Furthermore, while this study is limited to a small sample size and number of materials, additional study of other materials, as well as the study of additional samples of materials that were assessed here could provide a strong indication for useful development pathways for impact assessment models and the development of new characterization factors. One other potential that this discussion illustrates is that there could be an argument for additions to fate and exposure modeling in LCA. In particular, the further development of accounting for embedded toxicity could help to capture some of the exposure discrepancies between the impacts expected in indoor environmental quality and the more global emission compartments (e.g., urban or rural air) traditionally included in LCA fate and exposure modeling, such as that found in e.g., USEtox [29] or USES-LCA 2.0 [44]. Additionally, the issues raised in this article with regard to temporal scope echo some of the issues presented in the literature on dynamic life cycle assessment [45-47] with regard to the handling of future emissions. This is due to the long (potentially centuries) service life of buildings and building components, especially when considering the circular economy. Furthermore, there is some potential for temporal differentiation methods that have been developed within dynamic life cycle assessment to aid in the development of models for approximating embedded toxicity and the need for temporal resolution in the assessment of exposure in indoor environmental quality.

Lastly, the characterization factors are converted from CTUh to DALY using weighting factors, however, these weighting factors appear to not consider age weighting. This may pose a concern and add uncertainties to buildings with specific uses (i.e., different uses in different use cycles, e.g., single-family house, kindergarten, or office building).

\subsection{Quantitative Results}

Comparing the embedded and embodied toxicological impact potential reveals a slightly larger toxicological footprint for both wood and concrete. However, if the impact is divided into carcinogenic and non-carcinogenic effects on human health, the embedded toxicity impacts stemming from carcinogenic effects from exposure to chemicals in wood and concrete are larger than the toxicological footprint impacts from carcinogenic effects. This suggests that the embedded toxicological impacts can be larger than the embodied chemicals. However, as presented in Figures 6 and 7, the embedded toxicological impacts are of considerable proportions and leaving these out would further hamper the uncertainty quantifying the toxicological impact potentials of the built environment.

An interesting observation is the fact that the embodied toxicities of both wood and concrete include the chemicals identified in the embedded toxicity for which characterization factors are available. These chemicals are easily identified as elementary flows in the system inventories of the concrete and wood product systems modeled in this paper. Naphthalene appears in both inventories, where it is used to quantify the toxicological footprint of both wood and concrete. The largest contribution of naphthalene induced toxicological impacts originates from the processes "market for sawnwood, softwood, dried $(\mathrm{u}=10 \%)$, planed" and "market for cement, Portland", respectively, and hence from processes also taking place prior to use of the concrete. Benzaldehyde, benzene, and hexane are also present in the system inventory of the concrete product system, and here the largest contribution of these chemicals stems from the "market for cement, Portland". Various other organic chemicals and heavy metals also appear in the inventories. However, pyridine is not present.

Another note that can be taken from the results of this study is found in the relative values for embodied and embedded toxicological impacts. While the circular economy is typically introduced to reduce the impacts of the built environment [4], whether through a reduction in the use of natural resources or a more holistic impact assessment, the understanding garnered through the quantification of embedded toxicological impacts shows a result that can run counter to this goal. The understanding that introducing the 
circular economy provides a pathway for toxic chemical exposure to humans highlights a need for caution in ensuring that a holistic picture of the results of the circular economy is accounted for. For example, in systems where the circular economy is optimized to reduce greenhouse gas emissions through the incorporation of a circular economy, it is possible that there would be a resultant increase in toxicological effects from impacts on indoor environmental quality due to the introduction of embedded toxic chemicals.

\section{Conclusions}

This article raises several questions. Of paramount importance is the question of whether LCA is presently capable of assessing circular economic models of building materials/components. To answer this question, one must consider the four ISO defined LCA steps "goal and scope", "inventory", "impact assessment" and "interpretation". Regarding the goal and scope, it is primarily the scoping issue which is considered a major issue in relation to circular economic models for building materials, since, in modeling buildings and components of the built environment in the circular economy, impacts must be accounted for that are induced by emissions potentially taking place hundreds of years in the future. This issue poses challenges for validating LCA approaches for the circular economy in the built environment, as the service life can exceed the typical time horizon of an LCA and poses issues with regard to the lack of knowledge of the future status quo and its impact on characterization factors. The inventory step is also a cause for major concern in relation to circular economic models for building materials since models and data capable of describing how chemicals are absorbed by building materials/components and migrate in the value chain across time and space are lacking.

In terms of impact assessment, it was illustrated through lack of coverage in the assessed building materials that the characterization models available today do not cover chemicals present in building materials that can be emitted during use. Thus, characterization models need to be further developed to enable the assessment of emissions from a product providing different services during its multiple use cycles. The issue of multiple use cycles with unknown provenance and fate necessitates the development of a more flexible setup than that of the exposure models applied in LCIA today. One might consider the need for developing characterization models where the user can select combinations of exposure scenarios. In addition, indoor exposure models also need to be developed for the characterization models, as the findings of this study confirm previous studies (e.g., [48]) of indoor environmental quality representing equal or greater potential impacts relative to external impacts. The interpretation step of LCA in terms of toxicological impacts also need further development to be capable of handling prospective normalization and weighting centuries into the future. Furthermore, compounding the issue of characterization, there is the inventory issue of uncertainty in provenance, where waste flows from decommissioned buildings are mixed, as is commonly done in Denmark, more extensive testing is needed to quantify the expected embedded toxicity of particular building components (e.g., concrete or wood).

One other common aspect to the challenges induced by circular economic models for building materials for all ISO defined steps of LCA is that the temporal perspective that needs to be considered is so large that neither forecasting nor foresight provides a simple or easy solution. A potential solution to these challenges could be scenarios equivalent (however much more detailed and reaching even further into the future) to the commonly known Shared Socioeconomic Pathways [49], which could be introduced as a form of sensitivity analysis.

The above-presented observations, questions, and challenges all lead to one very simple conclusion: If LCAs of circular economic models for building materials/components are to include toxicological impacts, which is necessary for providing a holistic picture of environmental impacts, then there is a need for continued method development. This potentially includes more focus on spatial and temporal coverage in addition to the further development of methods for quantifying and incorporating embedded toxicity into LCA. 
These challenges necessitate tremendous efforts to enable valid LCA of circular economic models for building materials/components, but they also present great opportunities for a better understanding of life cycle impacts assessment within the built environment.

Author Contributions: Conceptualization, M.B. and D.B.; validation, C.W.E.; formal analysis, C.W.E. and X.F.; resources, M.B.; data curation, C.W.E., D.B., X.F. and J.L.S.; writing-original draft preparation, C.W.E., D.B. and J.L.S.; writing-review and editing, M.B., C.W.E., D.B. and J.L.S.; supervision, M.B. and D.B.; funding acquisition, D.B. All authors have read and agreed to the published version of the manuscript.

Funding: This research received funding from the Aase og Ejnar Danielsens Fond [19-30-0479].

Data Availability Statement: All data used in this article are available in the article text or in publicly available databases as cited in the text.

Acknowledgments: The authors would like to gratefully acknowledge the research support of "Aase og Ejnar Danielsens Fond". Further acknowledgement goes to RGS Nordic A/S for providing the building materials used in the laboratory setup.

Conflicts of Interest: The authors declare no conflict of interest, and the funders had no role in the design of the study; in the collection, analyses, or interpretation of data; in the writing of the manuscript, or in the decision to publish the results.

\section{Appendix A}

Table A1. Chemical properties of identified chemicals in wood and concrete. The table includes name, CAS no. molecular weight $(\mathrm{g} / \mathrm{mol})$, water partition coefficient $(-)$, melting point $\left({ }^{\circ} \mathrm{C}\right)$, boiling point $\left({ }^{\circ} \mathrm{C}\right)$, vapor pressure $(\mathrm{mmHg})$, and Henry's law constant $(\mathrm{L} \cdot \mathrm{atm} / \mathrm{mol})$. All information is gathered from [28]. * denotes the characterized chemicals.

\begin{tabular}{|c|c|c|c|c|c|c|c|}
\hline Name & CAS No & $\begin{array}{c}\text { Molecular } \\
\text { Weight } \\
\text { (g/mol) }\end{array}$ & $\begin{array}{c}\text { Water } \\
\text { Partition } \\
\text { Coefficient (-) }\end{array}$ & $\begin{array}{c}\text { Melting Point } \\
\left({ }^{\circ} \mathrm{C}\right)\end{array}$ & $\begin{array}{l}\text { Boiling Point } \\
\left({ }^{\circ} \mathrm{C}\right)\end{array}$ & $\begin{array}{l}\text { Vapor } \\
\text { Pressure } \\
(\mathrm{mmHg})\end{array}$ & $\begin{array}{c}\text { Henrys Law } \\
\text { Constant } \\
(\mathrm{L} \cdot \mathrm{atm} / \mathrm{mol})\end{array}$ \\
\hline 1-Heptene & $592-76-7$ & 98.19 & 3.99 & -119 & 93.6 & 59.3 & 0.236 \\
\hline 2,4-Hexadieneoic acid & $110-44-1$ & 112.128 & 1.33 & 134 & 228 & 0.138 & $6.65 \times 10^{-7}$ \\
\hline 3-Heptene-2,6-dione & $99809-46-8$ & 126.155 & 0.206 & -6.08 & 201 & 0.401 & $1.11 \times 10^{-6}$ \\
\hline Benzaldehyde* & $100-52-7$ & 106.124 & 1.48 & -42.5 & 179 & 1.27 & $2.67 \times 10^{-5}$ \\
\hline Benzene * & $71-43-2$ & 78.114 & 2.13 & 5.42 & 80 & 94.8 & $5.55 \times 10^{-3}$ \\
\hline Decane & $124-18-5$ & 142.286 & 5.01 & -29.9 & 174 & 1.43 & 0.154 \\
\hline Hexane * & $110-54-3$ & 86.178 & 3.9 & -99.1 & 68.6 & 151 & $4.92 \times 10^{-1}$ \\
\hline Naphthalene * & $91-20-3$ & 128.174 & 3.3 & 80.3 & 218 & $8.50 \times 10^{-2}$ & $4.40 \times 10^{-4}$ \\
\hline Pyridine * & $110-86-1$ & 79.102 & 0.65 & -41.9 & 115 & 20.8 & $1.10 \times 10^{-5}$ \\
\hline $\begin{array}{l}\text { 2-Norpinene, } \\
\text { 3,6,6-trimethyl }\end{array}$ & $4889-83-2$ & 136.238 & 4.36 & -59.6 & 160 & 2.96 & $8.20 \times 10^{-2}$ \\
\hline 3-carene & $13466-78-9$ & 136.238 & 4.38 & 22.3 & 170 & 3.69 & $6.42 \times 10^{-2}$ \\
\hline
\end{tabular}

Table A2. Chemical properties of identified chemicals in wood and concrete. The table includes name, CAS no. molecular weight $(\mathrm{g} / \mathrm{mol})$, water partition coefficient $(-)$, melting point $\left({ }^{\circ} \mathrm{C}\right)$, boiling point $\left({ }^{\circ} \mathrm{C}\right)$, vapor pressure $(\mathrm{mmHg})$, and Henry's law constant $(\mathrm{L} \cdot \mathrm{atm} / \mathrm{mol})$. All information is gathered from [28].

\begin{tabular}{|c|c|c|c|c|c|c|c|}
\hline Name & CAS No & $\begin{array}{c}\text { Molecular } \\
\text { Weight } \\
\text { (g/mol) }\end{array}$ & $\begin{array}{c}\text { Water Partition } \\
\text { Coefficient (-) }\end{array}$ & $\begin{array}{l}\text { Melting Point } \\
\left({ }^{\circ} \mathrm{C}\right)\end{array}$ & $\begin{array}{l}\text { Boiling Point } \\
\left({ }^{\circ} \mathrm{C}\right)\end{array}$ & $\begin{array}{l}\text { Vapor } \\
\text { Pressure } \\
(\mathrm{mmHg})\end{array}$ & $\begin{array}{c}\text { Henrys Law } \\
\text { Constant } \\
(\mathrm{L} \cdot \mathrm{atm} / \mathrm{mol})\end{array}$ \\
\hline$\alpha$-Longipinene & 5989-08-2 & 204.357 & 5.88 & 7.48 & 254 & $1.74 \times 10^{-2}$ & $5.22 \times 10^{-3}$ \\
\hline$\alpha$-Pinene & $80-56-8$ & 136.238 & 4.83 & -59.7 & 155 & 4.75 & $1.34 \times 10^{-1}$ \\
\hline$\alpha$-Terpinene & $99-86-5$ & 136.238 & 4.25 & -27.4 & 174 & 1.53 & $2.38 \times 10^{-2}$ \\
\hline$\alpha$-Terpineol & $98-55-5$ & 154.253 & 2.98 & 34.8 & 217 & $4.23 \times 10^{-2}$ & $2.23 \times 10^{-6}$ \\
\hline Bornylacetate & $5655-61-8$ & 196.29 & 3.82 & 38.7 & 223 & 0.127 & $5.16 \times 10^{-4}$ \\
\hline Cyclohexene & $110-83-8$ & 82.146 & 2.86 & -104 & 83.3 & 89 & $4.55 \times 10^{-2}$ \\
\hline Hexanal & $66-25-1$ & 100.161 & 1.78 & -44 & 129 & 11.3 & $2.13 \times 10^{-4}$ \\
\hline
\end{tabular}




\section{References}

1. Hauschild, M.; Rosenbaum, R.K.; Olsen, S. Life Cycle Assessment: Theory and Practice, 1st ed.; Springer International Publishing: Cham, Switzerland, 2018; ISBN 978-3-319-56474-6.

2. Curran, M.A. A Brief History of Life-Cycle Assessment; U.S. Environmental Protection Agency: Washington, DC, USA, 2006.

3. Sohn, J.L.; Kalbar, P.P.; Banta, G.T.; Birkved, M. Life-cycle based dynamic assessment of mineral wool insulation in a Danish residential building application. J. Clean. Prod. 2017, 142, 3243-3253. [CrossRef]

4. Hart, J.; Adams, K.; Giesekam, J.; Tingley, D.D.; Pomponi, F. Barriers and drivers in a circular economy: The case of the built environment. Procedia CIRP 2019, 80, 619-624. [CrossRef]

5. Eberhardt, L.; van Stijn, A.; Rasmussen, F.; Birkved, M.; Birgisdottir, H. Development of a life cycle assessment allocation approach for circular economy in the built environment. Environ. Int. 2020, 12, 9579.

6. Goldstein, B.; Rasmussen, F.N. LCA of Buildings and the Built Environment. In Life Cycle Assessment; Springer: Cham, Switzerland, 2018; pp. 695-722.

7. Colangelo, F.; Navarro, T.G.; Farina, I.; Petrillo, A. Comparative LCA of concrete with recycled aggregates: A circular economy mindset in Europe. Int. J. Life Cycle Assess. 2020, 25, 1790-1804. [CrossRef]

8. Munaro, M.R.; Tavares, S.F.; Bragança, L. Towards circular and more sustainable buildings: A systematic literature review on the circular economy in the built environment. J. Clean. Prod. 2020, 260, 121134. [CrossRef]

9. Li, D.; Tao, M.; Vieira, J.; Suh, S. The Effects of Incorporating Non-linearity in LCA: Characterizing the Impact on Human Health. Front. Sustain. 2020, 1, 1-9. [CrossRef]

10. Sohn, J.L.; Kalbar, P.P.; Birkved, M. Life cycle based dynamic assessment coupled with multiple criteria decision analysis: A case study of determining an optimal building insulation level. J. Clean. Prod. 2017, 162, 449-457. [CrossRef]

11. Dansk Standard. DS/CEN/TR 17005: 2016; Technical Report for the Assessment of the Environmental Performance of Buildings. Danish Standards: Charlottenlund, Denmark, 2016.

12. Huang, L.; Anastas, N.; Egeghy, P.; Vallero, D.A.; Jolliet, O.; Bare, J. Integrating exposure to chemicals in building materials during use stage. Int. J. Life Cycle Assess. 2019, 24, 1009-1026. [CrossRef] [PubMed]

13. Ibn-Mohammed, T.; Reaney, I.M.; Koh, S.C.L.; Acquaye, A.; Sinclair, D.C.; Randall, C.A.; Abubakar, F.H.; Smith, L.; Schileo, G.; Ozawa-Meida, L. Life cycle assessment and environmental profile evaluation of lead-free piezoelectrics in comparison with lead zirconate titanate. J. Eur. Ceram. Soc. 2018, 38, 4922-4938. [CrossRef]

14. Hauschild, M.Z.; Rosenbaum, R.K.; Olsen, S.I. Life Cycle Assessment; Springer International Publishing: Cham, Switzerland, 2018.

15. de Carvalho Araújo, C.K.; Salvador, R.; Moro Piekarski, C.; Sokulski, C.C.; de Francisco, A.C.; de Carvalho Araújo Camargo, S.K. Circular economy practices on wood panels: A bibliographic analysis. Sustainability 2019, 11, 1057. [CrossRef]

16. SigmaAldrich. SPME for GC Analysis; Sigma Aldrich: St. Louis, MO, USA, 2020.

17. Eurofins Product Testing. Rådgivning om Test af Byggematerialer. Available online: https://www.eurofins.dk/product-testing/ vaelg-service/raadgivning/raadgivning-om-test-af-byggematerialer/ (accessed on 13 December 2021).

18. James, J.P.; Yang, X. Emissions of Volatile Organic Compounds from Several Green and Non-Green Building Materials: A Comparison. Indoor Built Environ. 2005, 14, 69-74. [CrossRef]

19. Hansen, O.C. Træbeskyttelsesmidler og Imprægneret Træ; Miljøstyrelsen: Copenhagen, Denmark, 1997.

20. Chemicals in Products. Danish Environmental Protection Agency. Available online: https://eng.mst.dk/chemicals/chemicals-inproducts/ (accessed on 13 December 2021).

21. Miljøstyrelsen. Forurenende Stoffer i Beton og Tegl; Miljøstyrelsen: Copenhagen, Denmark, 2015; ISBN 9788793352995.

22. Miljøstyrelsen. Identifikation af Problematiske Stoffer i Overfladebehandlet Tegl og Beton, Herun-Der Eternitplader, Fiberarmeret Beton, Klinker og Sanitet; Miljøstyrelsen: Copenhagen, Denmark, 2019.

23. Miljøstyrelsen. Udredning af Teknologiske Muligheder for at Genbruge og Genanvende Beton; Miljøstyrelsen: Copenhagen, Denmark, 2015.

24. National Institute of Standards and Technology-NIST. Standard Reference Database 1A, v17; National Institute of Standards and Technology: Gaithersburg, MD, USA, 2017.

25. Baidoo, E.E.K.; Teixeira Benites, V. Mass Spectrometry-Based Microbial Metabolomics: Techniques, Analysis, and Applications. In Microbial Metabolomics; Humana Press: New York, NY, USA, 2019; pp. 11-69.

26. Sparkmann, O.D.; Penton, Z.; Kitson, F.G. Gas Chromatography and Mass Spectrometry: A Practical Guide, 2nd ed.; Elsevier Science \& Technology: Amsterdam, The Netherlands, 2011.

27. Pavia, D.L.; Lampmann, G.M.; Kriz, G.S.; Vyvyan, J.R. Introduction To Spectroscopy, 5th ed.; Cengage Learning: Stamford, CT, USA Bellingham, WA, USA, 2015.

28. Fazio, S.; Castellani, V.; Sala, S.; Schau, E.; Secchi, M.; Zampori, L.; Diaconu, E. Supporting Information to the Characterisation Factors of Recommended EF Life Cycle Impact Assessment Methods: New Methods and Differences with ILCD; Technical Report for Environment and Climate Change; Publications Office of the European Union: Luxembourg, 2018.

29. Rosenbaum, R.K.; Huijbregts, M.A.J.; Henderson, A.D.; Margni, M.; McKone, T.E.; Van De Meent, D.; Hauschild, M.Z.; Shaked, S.; Li, D.S.; Gold, L.S.; et al. USEtox human exposure and toxicity factors for comparative assessment of toxic emissions in life cycle analysis: Sensitivity to key chemical properties. Int. J. Life Cycle Assess. 2011, 16, 710-727. [CrossRef] 
30. Fantke, E.P.; Bijster, M.; Guignard, C.; Hauschild, M.; Huijbregts, M.; Jolliet, O.; Kounina, A.; Magaud, V.; Margni, M.; Mckone, T.; et al. UNEP/SETAC scientific consensus model for characterizing human toxicological and ecotoxicological impacts of chemical emissions in life cycle assessment. In USEtox ${ }^{\circledR} 2.0$ Documentation; Version 1.1. USEtox ${ }^{\circledR}$; International Center Hosted at the Technical University of Denmark: Lyngby, Demark, 2017. [CrossRef]

31. Huijbregts, M.A.J.; Linda, À.; Rombouts, J.A.; Ad, À.; Ragas, M.J.; Van De Meentà, D. Human-Toxicological Effect and Damage Factors of Carcinogenic and Noncarcinogenic Chemicals for Life Cycle Impact Assessment. Integr. Environ. Assess. Manag. Int. J. 2005, 1, 181-244. [CrossRef] [PubMed]

32. World Health Organization Regional Office for Europe. WHO Guidelines for Indoor Air Quality, Selected Pollutants; World Health Organization: Geneva, Switzerland, 2010.

33. World Health Organization. Metrics: Disability-Adjusted Life Year (DALY); World Health Organization: Geneva, Switzerland, 2016.

34. GreenDelta GmbH. OpenLCA Nexus. Available online: https://nexus.openlca.org/ (accessed on 13 December 2021).

35. Wernet, G.; Bauer, C.; Steubing, B.; Reinhard, J.; Moreno-ruiz, E.; Weidema, B. The ecoinvent database version 3 (part I): Overview and methodology. Int. J. Life Cycle Assess. 2016, 3, 1218-1230. [CrossRef]

36. NCBI-National Center for Biotechnology Information; PubChem. PubChem Database. Hexanal, CID=6184. Available online: https:/ / pubchem.ncbi.nlm.nih.gov/ compound/Hexanal\#section=DSSTox-Substance-ID (accessed on 13 December 2021).

37. United States Environmental Protection Agency. CompTox Chemicals Dashboard; United States Environmental Protection Agency: Washington, DC, USA. Available online: https://comptox.epa.gov/dashboard/ (accessed on 13 December 2021).

38. GreenDelta. OpenLCA, V 1.10; GreenDelta: Berlin, Germany, 2021.

39. United States Environmental Protection Agency. Assessment and Control of Indoor Air Pollution; United States Environmental Protection Agency: Washington, DC, USA, 1986.

40. International Agency for Reseacrh on Cancer; World Health Organization. Iarc Monographs on the Identification of Carcinogenic Hazards to Humans; World Health Organization: Geneva, Switzerland, 2019; Available online: https://monographs.iarc.who.int/ (accessed on 13 December 2021).

41. Logue, J.M.; Mckone, T.E.; Sherman, M.H.; Singer, B.C. Hazard assessment of chemical air contaminants measured in residences. Indoor Air 2011, 21, 92-109. [CrossRef] [PubMed]

42. European Chemicals Agency. 21551 Chemicals on EU Market Now Registrered, ECHA/PR/18/10; European Chemicals Agency: Helsinki, Finland, 2018.

43. Healthy Building Network. Pharos; Healthy Building Network: Washington, DC, USA, 2022. Available online: https:// pharosproject.net/about (accessed on 13 December 2021).

44. Van Zelm, R.; Huijbregts, M.A.J.; Van De Meent, D. USES-LCA 2.0-a global nested multi-media fate, exposure, and effects model. Int. J. Life Cycle Assess. 2009, 14, 282-284. [CrossRef]

45. Levasseur, A.; Lesage, P.; Margni, M.; Deschenes, L.; Samson, R. Considering Time in LCA: Dynamic LCA and its application to global warming impact assessment. Environ. Sci. Technol. 2010, 44, 3169-3174. [CrossRef] [PubMed]

46. Beloin-Saint-Pierre, D.; Albers, A.; Hélias, A.; Tiruta-Barna, L.; Fantke, P.; Levasseur, A.; Benetto, E.; Benoist, A.; Collet, P. Addressing temporal considerations in life cycle assessment. Sci. Total Environ. 2020, 743, 140700. [CrossRef] [PubMed]

47. Sohn, J.; Kalbar, P.; Goldstein, B.; Birkved, M. Defining Temporally Dynamic Life Cycle Assessment: A Review. Integr. Environ. Assess. Manag. 2020, 16, 314-323. [CrossRef] [PubMed]

48. Collinge, W.; Landis, A.; Jones, A. Integrating Indoor environmental quality metrics in a dynamic life cycle assessment framework for buildings. In Proceedings of the 2012 IEEE International Symposium on Sustainable Systems and Technology (ISSST), Boston, MA, USA, 16-18 May 2012.

49. Riahi, K.; van Vuuren, D.P.; Kriegler, E.; Edmonds, J.; O’Neill, B.C.; Fujimori, S.; Bauer, N.; Calvin, K.; Dellink, R.; Fricko, O.; et al. The Shared Socioeconomic Pathways and their energy, land use, and greenhouse gas emissions implications: An overview. Glob. Environ. Chang. 2017, 42, 153-168. [CrossRef] 